\title{
Entendimento de professores universitários sobre o seu fazer: ensino como atividade preponderante e extensão como atividade ainda periférica
}

\author{
Understanding of university professors about their practices: teaching as prevailing \\ activity and extension as still peripheral activity
}

\author{
Cátia Maria Nehring* \\ Isabel Koltermann Battisti** \\ Marta Cristina Cezar Pozzobon ${ }^{* *+}$
}

\section{Resumo}

As dimensões ensino, pesquisa e extensão são tratadas de diferentes formas a partir da natureza e da organização acadêmica das instituições de educação superior. A indissociabilidade entre elas possibilita o estabelecimento e o desenvolvimento do espírito científico universal. Esta escrita baseia-se em uma investigação que objetiva discutir a constituição do professor da educação superior e levanta as seguintes questões: qual relação os professores que atuam em universidades estabelecem entre suas atividades de ensino, de pesquisa e de extensão? Eles compreendem a indissociabilidade entre as três atividades como política de suas instituições? Qual é o papel atribuído à extensão a partir da perspectiva de que esta dimensão é um elemento de diálogo e aprendizagem entre universidade e sociedade? Os dados empíricos consideraram um questionário respondido por professores que atuam em universidades com jornada de trabalho de tempo integral. As análises organizaram-se a partir de duas unidades e consideram proposições apresentadas, especialmente, por Mazzilli (2011), Síveres $(2011,2013)$ e Dias e Ketzer $(2007)$ e identificadas no documento "Plano nacional de graduação: um projeto em construção" (FORGRAD, 2004). De acordo com o levantamento, o princípio da indissociabilidade entre ensino, pesquisa e extensão não está estabelecido, essa relação precisa ser construída como uma política institucional, e a atividade de extensão ainda é percebida como atividade periférica no fazer do professor universitário.

Palavras-chave: Atividades de ensino. Atividade de extensão. Princípio pedagógico da indissociabilidade. Professor universitário.

Recebido em 22/03/2018 - Aprovado em 18/06/2018

http://dx.doi.org/10.5335/rep.v25i3.8569

Doutora em Educação pela Universidade Federal de Santa Catarina. Docente do Programa de Pós-Graduação em Educação nas Ciências da Universidade Regional do Noroeste do Estado do Rio Grande do Sul (Unijuí). Líder do Grupo de Estudos em Educação Matemática (Geem). E-mail: catneh@hotmail.com

* Doutora em Educação nas Ciências pela Unijuí. Docente do Departamento de Ciências Exatas e Engenharias na mesma instituição. Coordenadora de subprojeto na área de matemática do Pibid/Unijuí. E-mail: isabel.battisti@unijui. edu.br

*** Doutora em Educação pela Unisinos. Professora adjunta nos cursos de Pedagogia e mestrado profissional em Educação na Universidade Federal do Pampa, campus Jaguarão. E-mail: marta.pozzobon@hotmail.com 


\title{
Abstract
}

\begin{abstract}
Teaching, research and extension dimensions have been treated in different ways from the academic nature and organization of the Higher Education Institutions. The inseparability among them enables the establishment and the development of a universal scientific spirit. This writing is based on an investigation, which aims to discuss the constitution of higher education professor, and it has as a problematic the following questions: what is the relationship that professors who work in universities have established among their activities of teaching, research and extension? Do they understand the inseparability among the three activities as the politics of their institutions? What is the role of extension from the perspective of this dimension, as an element of dialogue and learning between University and Society? The empirical data considered a questionnaire answered by university professors, with a full-time working day. The analyses are based on two units and they considered propositions presented especially by Mazzilli (2011), Síveres (2011, 2013), Dias and Ketzer (2007), and "Plano nacional de graduação: um projeto em construção" (FORGRAD, 2004). They indicate that the principle of indissociability among teaching, research and extension is not established, and this relationship needs to be constructed as an institutional policy. Moreover, extension activity is still perceived as peripheral activity in the university professors' practice.
\end{abstract}

Keywords: Extension activity. Pedagogical principle of indissociability. Teaching activities. University professor.

\section{Introdução}

No Brasil, nas últimas duas décadas, o contexto social e as políticas públicas viabilizaram uma expansão da educação superior. Na década de 1960, de acordo com documento publicado no Fórum de Pró-Reitores de Graduação das Universidades Brasileiras (Forgrad) (2004), o país contava com cerca de 100 instituições de educação superior (IES) e em torno de 100.000 estudantes. Atualmente, conforme dados obtidos no Censo da Educação Superior 2016, Notas Estatísticas (BRASIL, 2016), há 2.407 IES no Brasil, que, conforme sua organização acadêmica, classificam-se em: centro federal de educação tecnológica ou instituto federal de educação, ciência e tecnologia (40); centro universitário (166); faculdade (2004); e universidade (197). Neste censo, considera-se um total de 8.048.701 estudantes matriculados e 384.094 professores com vínculo.

De acordo com Gomes, "[...] a evolução do ensino superior brasileiro é um campo acadêmico complexo, rodeado por uma grande heterogeneidade de instituições, cada qual dotada de peculiaridades e características próprias [...]" (2010, p. 592). A expansão da educação superior (FORGRAD, 2004) apresenta vários problemas estruturais significativos e não ocorre de modo homogêneo e equilibrado. Tais aspectos, aliados à heterogeneidade das instituições, ao atendimento a estudantes com perfis sociais variados, à demanda por novos professores com titulação de mestres e doutores sem experiência docente, à complexidade da construção do conhecimento para além da informação, têm gerado estudos e pesquisas centrados na formação, na constituição e na atuação do professor da educação superior, visando a subsidiar 
ações capazes de articular o ensino, a pesquisa e a extensão, dimensões propostas na Constituição federal de 1988, como função da universidade.

As três dimensões, ensino, pesquisa e extensão, são consideradas e tratadas de diferentes formas a partir da natureza e da organização acadêmica das IES. A natureza e as respectivas prerrogativas acadêmicas das IES são, conforme o art. 12 do Decreto no 5.773 (BRASIL, 2006), credenciadas como: faculdades, centros universitários e universidades. Como universidades, conforme trata o art. 52 da Lei nº 9.394 (BRASIL, 1996), são designadas as

[...] instituições pluridisciplinares de formação dos quadros profissionais de nível superior, de pesquisa, de extensão e de domínio e cultivo do saber humano, que se caracterizam por: I - produção intelectual institucionalizada mediante o estudo sistemático dos temas e problemas mais relevantes, tanto do ponto de vista científico e cultural, quanto regional e nacional; II - um terço do corpo docente, pelo menos, com titulação acadêmica de mestrado ou doutorado; III - um terço do corpo docente em regime de tempo integral (BRASIL, 1996).

As IES não universitárias, como os centros universitários e as faculdades (FORGRAD, 2004), não têm autonomia de gestão, são administradas em estrita subordinação burocrática ao Ministério da Educação (MEC) e ao Conselho Nacional de Educação (CNE) e isentas, por atribuição da lei, muitas vezes das atividades de pesquisa e de extensão. Ainda de acordo com o documento, a isenção das atividades de pesquisa e de extensão, com poucas exceções, leva ao desenvolvimento de um ensino reprodutivista em relação ao conhecimento acumulado do passado e às demandas da sociedade atual. Muitas vezes, a desobrigação da função de produção do saber e de relação com a comunidade pode gerar práticas de ensino configuradas como reprodutivas ou repetidoras de estágios de formação rapidamente ultrapassáveis. Diante das colocações, no documento afirma-se que:

Um dos grandes desafios para a formação universitária contemporânea é, sem dúvida, o da geração de espírito científico universal, de modo a ensejar a todos os egressos condições para acompanhar a evolução das atividades produtivas e humanas em qualquer campo de atuação e a necessária "educação permanente". A quebra do princípio pedagógico da indissociabilidade entre ensino, pesquisa e extensão gera caminhos sem saída (FORGRAD, 2004, p. 24).

Sob esses entendimentos, a indissociabilidade e o desenvolvimento efetivo das dimensões do ensino, da pesquisa e da extensão, como princípio pedagógico, possibilitam o estabelecimento e o desenvolvimento do espírito científico universal que é condição para uma educação permanente e é "[...] a resposta necessária aos desafios do projeto de desenvolvimento de uma nação que exige, de seus filhos, formação científica sólida, competência técnica, lucidez política associada a compromisso ético" (FORGRAD, 2004, p. 229). 
Entendemos, assim, em acordo com Maciel e Mazzilli, que a indissociabilidade entre ensino, pesquisa e extensão é um princípio que "[...] reflete um conceito de qualidade do trabalho acadêmico que favorece a aproximação entre universidade e sociedade, a autorreflexão crítica, a emancipação teórica e prática dos estudantes e o significado social do trabalho acadêmico" (2010, p. 30).

Com isso, enfatizamos que as universidades são as IES cujas atividades-fim são o ensino, a pesquisa e a extensão em todas as áreas do conhecimento humano, e essas dimensões estão demarcadas pelo princípio pedagógico da indissociabilidade. O que nos leva a corroborar a ideia de que o professor que atua em universidades encontra-se inserido em condições institucionais favoráveis ao trabalho pedagógico de construção de conhecimentos por meio da mediação entre o ensino, a pesquisa $\mathrm{e}$ a extensão (FRANCO, 2009).

Porém, entendemos que a indissociabilidade entre o ensino, a pesquisa e a extensão, apesar de prevista na Lei de Diretrizes e Bases da Educação Nacional (LDBEN), e de, ainda, ter sido muito defendida enquanto política pública, não foi efetivada em sua plenitude em muitas IES.

A partir de Sampaio e Freitas (2010), podemos conferir ao ensino a responsabilidade da socialização dos saberes já acumulados pela humanidade; à pesquisa, a produção de novos saberes, buscando alargar as fronteiras do conhecimento humano; e à extensão, as aplicabilidades social e ética dos conhecimentos acumulados. Já Menezes e Síveres (2011) defende que a extensão tem um papel determinante na constituição da identidade de uma IES e de sua relação direta com as demandas sociais. Por isso, pensar em indissociabilidade implica refletir sobre questões institucionais fundantes, como missão, filosofia, visão de conhecimento e educação.

Nesse sentido, defendemos que à extensão cabem o estabelecimento de diálogos com a sociedade na construção dinâmica e orgânica de um projeto educacional, bem como a participação ativa de quem nela atua. No entendimento de Síveres (2011), no contexto da pós-modernidade, só é possível atuar na conjuntura da dinâmica global partindo do pressuposto de que uma inserção e uma compreensão da realidade são fundamentais para o exercício da educação superior, o que ratifica ainda mais a importância da extensão.

A LDBEN conceitua extensão como "o processo educativo, cultural e científico que articula o Ensino e a Pesquisa de forma indissociável e viabiliza a relação transformadora entre Universidade e Sociedade" (BRASIL, 1996). Na concepção de Síveres (2013), a extensão pode ser compreendida como um jeito de ser, uma maneira de dialogar e uma possibilidade de aprender: (1) um jeito de ser, uma vez que se constitui a partir de uma diretriz capaz de revelar a essência institucional na realidade contemporânea, considerando aspectos como contextualização geo- 
política, construção do conhecimento e comunicação dos saberes; (2) uma maneira de dialogar, visto que possibilita o constante diálogo pluridirecional e multidimensional entre instituição e sociedade, contribuindo com o sentido da pessoa e da história, pautando o processo educativo como uma ação de reflexão e promovendo possibilidades diferenciadas de experiências educativas; e (3) uma possibilidade de aprender, uma vez que se constitui como eixo transversal para atividades acadêmicas de ensino e pesquisa, promovendo a articulação entre teoria e prática e a integração entre instituição e sociedade, considerando aspectos como tempo, espaço e processo de aprendizagem.

Com isso, destacamos que esta prática ainda está distante de alguns professores que atuam nas universidades. Em muitas IES, a prática realizada por seus professores, a partir de suas políticas, apresenta a extensão ainda como o elo fraco do tripé de indissociabilidade proposto pela LDBEN de 1996. De acordo com Demo (2004), a extensão ser considerada apenas a "prima pobre", a transferência do ensino mostra o empobrecimento do ensino e, ao mesmo tempo, nega o papel e o espírito da extensão universitária.

Nesse sentido, ponderamos que, para a atuação na educação superior, não se faz necessária formação docente específica, mas uma formação lato sensu ou stricto sensu em determinada área de conhecimento, ${ }^{1}$ pois as políticas públicas não apresentam orientações diretas para a formação do profissional da educação superior. As políticas ${ }^{2}$ determinam parâmetros de qualidade institucional e propõe que a formação para a atuação na educação superior fique a cargo de ações individuais e das instituições. ${ }^{3} \mathrm{O}$ professor que atua no ensino superior se constitui professor no exercício da docência, e, também, que as atividades de ensino, de pesquisa e de extensão são determinantes em suas ações profissionais na educação superior.

Dessas discussões, delimitamos o problema enfrentado e nos propomos a compreender, a partir do entendimento de um grupo de professores que atua na educação superior, mais especificamente em universidades, seus fazeres em relação à extensão e à indissociabilidade entre o ensino, a pesquisa e a extensão, considerando a constituição de professor universitário. Delimitamos as seguintes questões: qual relação os professores que atuam em universidades estabelecem entre suas atividades de ensino, de pesquisa e de extensão? Eles compreendem a indissociabilidade entre as três atividades como política de suas instituições? Qual é o papel atribuído à extensão a partir da perspectiva de que esta dimensão é um elemento de diálogo e aprendizagem entre universidade e sociedade? 


\section{Caminho metodológico}

Os procedimentos metodológicos utilizados nesta produção foram delineados com os intuitos de: compreender a ação do professor universitário no âmbito da educação superior a partir do seu fazer, considerando sua formação, sua constituição e as diferentes atividades que ultrapassam a tarefa de ministrar aulas; bem como entender os diferentes papéis da ação do professor na educação superior em relação às dimensões de ensino, pesquisa e extensão, priorizando a reflexão sobre o papel da extensão. A produção dos dados se efetivou a partir de uma atividade realizada em uma disciplina ${ }^{4}$ do doutorado em Educação nas Ciências.

O questionário, estruturado por 23 questões (objetivas e descritivas), é organizado em três blocos: perfil, trajetória e dimensões: ensino, pesquisa e extensão. Os dados obtidos a partir dos questionários geraram um banco de dados, no qual todos arquivos foram organizados em no programa Word, nomeados individualmente (P1, P2, etc.), tabulados em uma planilha do programa Excell, com a identificação de cada professor respondente (P1, P2, etc.). Em 2018, o banco de dados está constituído por 106 questionários, respondidos por professores em exercício na educação superior.

Visando ao atendimento do objetivo e da problemática propostos, considerando este banco de dados, realizamos um recorte para análise das informações. Delimitamos, a partir do perfil dos participantes da pesquisa, apenas os professores que atuam em IES, demarcando a universidade como organização acadêmica para análise. A partir dessa delimitação, propomos ainda outra, considerando o regime de trabalho na instituição em que atua, selecionando aqueles com dedicação de tempo integral.

Com esse recorte, consideramos na presente investigação professores que atuam em universidades, por nesta o fazer do professor estar explicitamente demarcado por ações de ensino, de pesquisa e de extensão. Mas, como em universidades também atuam professores com carga horária parcial, selecionamos apenas os professores que atuam em tempo integral, considerando, assim, sujeitos que, supostamente, têm tempo destinado para realizar ações que contemplam as três dimensões já citadas. Essas delimitações geraram um novo banco de dados, composto por 60 professores que trabalham em universidades, e deles 35 em tempo integral, sendo 20 do sexo feminino e 15 , masculino.

A partir da identificação dos professores, propomos um outro recorte. Consideramos as perguntas do questionário que vem ao encontro do nosso interesse de investigação. Explicitando: foi considerada uma questão objetiva que solicita ao professor que caracterize sua atuação profissional na educação superior e apre- 
senta como opção respostas relacionadas ao ensino, à pesquisa e à extensão. As outras perguntas consideradas são dissertativas e questionam: como o professor compreende a sua atuação na atividade de ensino; como caracteriza sua atuação na atividade de extensão; e se, em sua atuação, há relação entre as atividades de ensino, de pesquisa e de extensão.

Estabelecidos os critérios, geramos um novo banco de dados, que é objeto de análise na presente investigação. As informações serão tratadas quantitativa e qualitativamente. Entre as possibilidades que a pesquisa qualitativa pode assumir, optamos pela análise textual discursiva (ATD), segundo a perspectiva proposta por Moraes e Galiazzi (2013). Para os autores, a ATD

[...] é um processo integrado de análise e de síntese que se propõe a fazer uma leitura rigorosa e aprofundada de conjuntos de materiais textuais, com o objetivo de descrevê-los e interpretá-los no sentido de atingir uma compreensão mais complexa dos fenômenos e dos discursos a partir dos quais foram produzidos (MORAES; GALIAZZI, 2013, p. 112).

Dessa opção metodológica, as problematizações, as elaborações e os diálogos estabelecidos não se limitaram às análises empreendidas neste trabalho; conduziram-nos a selecionar recortes das respostas dos professores que evidenciavam elementos que nos interessavam na efetivação de exercícios de análises. Salientamos que os excertos, recortados do material empírico e apresentados no presente texto, estarão em itálico. As condições de análise se estabelecem, especialmente, a partir dos pressupostos teóricos apresentados por Mazzilli (2011) Sampaio e Freitas (2010), Síveres (2011, 2013), Menezes e Síveres (2011), Dias e Ketzer (2007) e Forgrad (1999, 2004).

Mediante os objetivos e a problemática da investigação, o referencial teórico considerado, a produção do material empírico e o entendimento de que a indissociabilidade entre pesquisa, ensino e extensão é determinante na constituição da profissionalização do professor da educação superior, consideramos dois focos de análises: ensino, atividade ainda preponderante dos professores que atuam em universidades, e extensão, atividade de diálogo e aprendizagem entre universidade e sociedade.

\section{Ensino, atividade preponderante dos professores que atuam em universidades}

Os professores sujeitos desta pesquisa atuam em universidades. Universidade, para efeitos legais, são IES que atendam no mínimo aos seguintes requisitos: estrutura pluridisciplinar, com oferta regular de cursos de graduação em pelo menos três campos do saber; programas consolidados de pós-graduação e programas institucionais de extensão em todos os campos do saber abrangidos pela institui- 
ção; pelo menos um terço do corpo docente em regime de tempo integral e pelo menos um terço dos docentes com titulação acadêmica de mestrado e/ou doutorado. Todos os sujeitos de nossa pesquisa são professores em regime de tempo integral e têm mestrado e/ou doutorado.

A partir do tratamento das informações geradas pela questão que solicitava ao docente que caracterizasse sua atuação profissional na educação superior, constatamos que nenhum dos professores considerados na pesquisa assinalou somente ensino, o que indica a atuação deles em outras dimensões constitutivas das atividades que caracterizam uma universidade. Essa constatação aproxima-se das proposições apresentadas por Mazzilli, quando afirma que o ensino

[...] por si só, pode servir à formação profissional, porém sem pesquisa e extensão, o ensino tende a reduzir-se ao aprendizado de técnicas, sem requerer compreensão do significado social desta mesma profissão e do profissional que a executa. A educação superior pautada apenas pelo ensino pode, no máximo, preparar mão de obra para o mercado de trabalho, mas longe está de qualquer aproximação com formação de sujeitos sociais (MAZZILLI, 2011, p. 15).

Dos 35 professores participantes da pesquisa, 29 indicaram que sua atuação profissional é caracterizada preponderantemente pelo ensino. Deles, 11 sinalizaram que atuam parcialmente em pesquisa, e 18, que atuam parcialmente em pesquisa e extensão, dos quais 4 apontaram que também atuam em gestão. Dois professores assinalaram o item Outra: um deles registrou "ensino e administrativo, extensão e pesquisa de maneira vinculada" (P39), e outro, "preponderantemente ensino e parcialmente pesquisa, extensão e gestão" (P36); dois professores caracterizaram sua atuação com ações preponderantemente em pesquisa e parcialmente em ensino; um professor indicou preponderantemente extensão e parcialmente ensino; e um professor não respondeu a questão. Assim, dos 35 professores sujeitos da pesquisa, 30 assinalaram que sua atividade preponderante é o ensino, o que referenda dados de pesquisas que indicam que a principal atuação do professor é a docência, exceto entre professores gestores e professores vinculados a programas stricto sensu.

A análise dessas informações possibilita constatar, pelo perfil dos referidos profissionais, que suas ações envolvem, além de ensino, atividades de pesquisa, de extensão e, em menor número, de gestão. Mas o que caracteriza as ações preponderantes deles são atividades de ensino aliadas às atividades, em torno de $60 \%$, de pesquisa e de extensão.

A partir do indicativo de que a atividade preponderante de um número significativo de professores sujeitos da pesquisa é o ensino, interessa-nos, neste momento, compreender a relação que esses professores estabelecem entre suas atividades de ensino, de pesquisa e de extensão, se eles compreendem a indissociabilidade entre 
as três atividades como política de suas instituições. Para tanto, propomos análises que consideram excertos das respostas descritivas apresentadas pelos professores, evidenciadas pela recorrência e, por hora, consideradas relevantes nas discussões propostas.

Constatamos que a análise do perfil dos professores sujeitos da pesquisa vem ao encontro de muitas das respostas obtidas quando questionados sobre como compreendem sua ação na atividade de ensino. P33 afirma: Vejo o ensino como a principal e mais importante atividade desenvolvida dentro da universidade. P17 entende que o ensino compreende a centralidade da atuação docente na universidade $\mathrm{e}$ amplia as discussões, dizendo que, pelo ensino, a universidade realiza uma de suas vocações que é a de inserir os educandos no âmbito da produção de conhecimento pela via da pesquisa, abrindo a eles a oportunidade de manifestar a dimensão poética e noética do existir. P17 explicita a relação que a pesquisa estabelece com suas ações de ensino. P41 afirma que a atuação no ensino é o campo de atuação prioritário, na sequência a ele, temos a extensão e a pesquisa (grifo nosso). $\mathrm{P} 41$ traz o ensino como sua ação prioritária e não explicita se são estabelecidas relações com a pesquisa ou com a extensão, relata que estas dimensões se colocam na sequência, mas não como inerentes ao processo de ensino. Essa ideia, de certa forma, se aproxima da apresentada por P42: a pesquisa e a extensãa são atividades paralelas e que muito delas trazem exemplos práticos para as aulas (grifo nosso). Para $\mathrm{P} 42$, as atividades de pesquisa e de extensão também não estão imbricadas ao ensino, aparecem no ensino a partir de exemplos práticos.

Mazzilli amplia as condições das análises, ao afirmar que a associação entre ensino, pesquisa e extensão

[...] constitui-se em fator desencadeador do processo de ensino: os conhecimentos já produzidos, ao serem colocados em prática, evidenciam lacunas, que se transformam em problemas para pesquisa, que retornam ao ensino sob a forma de novos conhecimentos, que serão adotados pela extensão e assim sucessivamente, num movimento constante e interativo entre as três funções (MAZZILLI, 2011, p. 15).

Como os profissionais indicaram as três atividades do fazer do professor da educação superior: ensino, pesquisa e extensão, pode haver possibilidades de que, em suas ações, articulem atividades constitutivas dessas três dimensões do fazer das IES, e de que esta articulação seja desencadeadora de processos de ensino. Mas a associação entre pesquisa, extensão e ensino como desencadeadora dos processos de ensino propostos na abordagem apresentada por Mazzilli não foi percebida na análise das respostas apresentadas pelos professores sujeitos da pesquisa. P17 coloca a pesquisa como produção de conhecimento pela via da pesquisa, mas não faz referência à extensão. Salientamos que a questão considerada se refere a como os 
professores compreendem suas atividades de ensino, não faz referência à relação estabelecida entre ensino, pesquisa e extensão.

Ao analisar as respostas dos professores sobre suas compreensões acerca das atividades do ensino, constatamos, ainda com recorrência, a necessidade de uma formação ou uma atualização constante. Essa ideia é apresentada por P42: me atualizando sempre, conhecendo o estado da arte de minha área de atuação $e$ atualizando os meus componentes curriculares (grifo nosso). P38 também compartilha dessa perspectiva, ao afirmar: nas atividades que envolvem o ensino, sejam as aulas ministradas ou atividades complementares, busco estar atento a novas informações e resultados, tentando trazer aos alunos um pouco do ambiente científico atual, por meio de um planejamento, promovendo uma troca de conhecimentos (grifo nosso). Estes dois professores, de forma explícita, manifestam a necessidade de uma atualização, considerando sua área específica de saber. Esse ponto, não de forma tão explicita, permeia as respostas de outros professores.

Outros aspectos chamam a atenção, que apresentamos na constituição das análises. Um é mencionado por P37, quando explicita sua compreensão acerca da atuação nas atividades de ensino, considerando o processo de aprender a ser professor:

a aprendizagem da docência é um processo longo, marcado por vários movimentos de avanços e retrocessos em busca da autonomia docente. Nesta perspectiva, falar sobre como compreendo a minha atuação na atividade de ensino revela entendimentos/concepções que são provisórios(as), pois a cada momento há a apropriação de saberes e fazeres novos necessários a prática pedagógica (grifos nossos).

P52, de certa forma, corrobora com P37 ao afirmar que, para atuarmos como professores, há necessidade de uma constante formação, precisamos buscar novas abordagens para conseguir atender a proposição dos cursos e as necessidades dos alunos (grifo nosso). P52 também faz referência a necessidade de conseguir atender a proposição dos cursos. Esse entendimento também é apresentado por P41: Minha atuação faz parte de um todo que depende também dos outros componentes curriculares que compõem o curso, no qual trabalho. Por isso é importante que o ensino seja pensado no coletivo do curso, de forma interdisciplinar (grifos nossos).

P37, P52 e P41 apresentam considerações relevantes para compreendermos a atividade de ensino: uma consiste em entender como o sujeito inserido na educação superior se constitui como docente. Outra, não menos importante, abordada por P52, considera as necessidades dos estudantes. A ideia implícita, entre outras, é a do processo de ensino-aprendizagem deste sujeito que está na educação superior. Esse é mais um aspecto fundante, ao organizar e propor atividades de ensino. Ou- 
tro ponto essencial é abordado por P52 e por P41, quando apontam o ensino a partir de um coletivo, considerando o curso e a forma como os diferentes componentes curriculares conversam e se articulam na efetivação de um perfil do egresso proposto pelo referido curso.

A análise dos excertos indica uma abordagem à formação pedagógica do professor, ou seja, a relação estabelecida entre o professor, sua área específica e os processos de ensinar e de aprender. Tal abordagem está intrínseca e fortemente relacionada aos saberes da ação docente. Nesse sentido, salientamos que

os saberes da ação docente [...] é o tipo de saber menos desenvolvido no reservatório de saberes do professor (curricular, disciplinar, da experiência etc.) e, paradoxalmente, o mais necessário à profissionalização do trabalho docente.

Na ausência de um saber da ação docente para ensinar, uma espécie de saber pedagógico universitário, o professorado do Ensino Superior continuará a recorrer à experiência, à tradição, ao bom senso, ao conteúdo, ao livro didático e à sua representação a respeito do que deve ensinar. Em suma, ele continuará usando saberes e estratégias privadas que não o diferenciam em nada, ou em quase dada, do cidadão comum [...] ou de qualquer outro profissional (DIAS; KETZER, 2007, p. 133).

Para e na constituição de saberes da ação docente pelo professor, defendemos a necessidade de se considerar a geração de um espírito científico universal, o que torna imperativo a compreensão, pela formação continuada, do princípio pedagógico, da indissociabilidade entre ensino, pesquisa e extensão. Considerando, assim, que o ensino se mostra como atividade preponderante dos professores sujeitos desta pesquisa, as análises marcam um aspecto que, no âmbito da educação superior, precisa, no mínimo, nos incomodar, para que seja tratado com maior pertinência, legitimando o fazer do professor neste nível de ensino. A legitimidade dada precisa ser construída e é de responsabilidade das IES, a partir da definição de política e programas de formação continuada de cada professor, considerando que o fazer docente implica apreender conceitos específicos.

\section{Extensão, atividade de diálogo e aprendizagem entre universidade e sociedade}

Visando à compreensão das possíveis relações que os professores estabelecem nas atividades que envolvem as dimensões estruturantes de uma universidade, com atenção especial para a extensão, recortamos, novamente, excertos que, no momento, possibilitam alguns exercícios de análise. Selecionamos e agrupamos excertos que apresentam aspectos comuns.

Dos 35 professores, um (P35) afirma que não há relação direta entre atividades de ensino, de pesquisa e de extensão: 
minhas atividades de ensino são definidas com base nas necessidades do curso que estou atuando. Minhas pesquisas estão relacionadas com áreas do meu interesse, que não necessariamente tem relação direta com um curso de graduação. Como nunca atuei na extensão, não tenho como relacioná-la com as demais atividades (grifos nossos).

Este registro difere dos demais: P35 é o único professor, dos sujeitos considerados nesta pesquisa, que afirma que, em suas ações como docente, não estabelece alguma relação entre ensino, pesquisa e extensão, o que nos leva a buscar o questionário respondido pelo referido professor. Ele, de acordo com o questionário, é doutorando e atua como docente na educação superior há 5 anos nos $1^{\circ}$ e $2^{\circ}$ semestres de cursos de graduação.

A análise das respostas nos leva a indicar que P35, mesmo atuando em uma universidade, ainda não a reconhece como uma instituição com status de universidade, o que pode acarretar fragilidades e/ou equívocos na sua constituição e atuação como professor universitário. Pois, como já dito, entendemos que um professor que atua neste nível de ensino e em uma IES com status de universidade deve se empoderar de um espírito científico universal, o que torna indispensável na sua ação efetiva enquanto professor o princípio da indissociabilidade entre ensino, pesquisa e extensão.

Alguns professores sujeitos da pesquisa afirmaram haver, sob diferentes concepções, algum tipo de relação entre ensino e pesquisa, pesquisa (como atividade preponderante) e ensino; outros indicaram uma relação entre ensino, pesquisa e extensão; e ainda outros, em minoria, afirmaram que, em suas atividades docentes, estabelecem relações entre ensino e extensão. Há ainda professores que reconheceram ser fundante a indissociabilidade entre as três dimensões, mas, considerando a sua atuação, não explicitaram as relações que efetivamente se estabelecem nas suas ações de professor.

O professor P93 indicou a atividade de extensão como preponderante e a atividade de ensino como parcial. Na questão que interroga se na atuação docente se estabelece relação entre as atividades de ensino, pesquisa e extensão, P93 afirma: Sim. Sempre em minha atuação procurei conciliar essas atividades de forma integradora e não de forma separada. Salientamos que, ao indicar a caracterização da atuação, P93 não fez referência à pesquisa. E a questão que interroga de forma direta como compreende a sua atuação na atividade de extensão não foi respondida por P93. A análise das respostas desse professor frustrou de certa forma nossas expectativas. Como foi o único sujeito da pesquisa que indicou a extensão como atividade preponderante, esperávamos respostas explicitas sobre seu fazer, considerando especialmente essa dimensão, o que não aconteceu. 
Já, P42 afirma que a pesquisa e a extensão são atividades paralelas e que muito delas trazem exemplos práticos para as aulas (grifo nosso). P36 explicita: a relação entre ensino, pesquisa e extensão existe na minha prática diária, pois em sala de aula utilizo exemplos de trabalhos de pesquisa (parte científica) e de troca de saberes com a comunidade (grifo nosso). E P33 afirma que o ensino está diretamente relacionado à pesquisa, pois serve de exemplos de como cada ensinamento é utilizado e é importante na prática (grifo nosso). Trazemos ainda o relato de $\mathrm{P} 45$, quando afirma: os referenciais que utilizo em sala de aula embasam minhas pesquisas e atividades de extensão. A análise indica que as atividades de ensino, de pesquisa e de extensão, para estes professores, perpassam uma relação estabelecida por exemplos; estamos denominando periférica esta relação, pois não percebemos, de forma explícita, uma relação que configura o princípio da indissociabilidade.

Apresentamos apenas um excerto sobre a relação entre ensino e extensão, porque essas relação que se estabelecem em outros trechos não são apresentadas pelo professor. Nesse sentido, P41 relata:

tenho desenvolvido um esforço permanente nesta relação, por exemplo, ao trabalhar no ensino com cursos de licenciatura, tratando da formação pedagógica específica, meus projetos de extensão focam problemáticas do ensino na educação básica, os quais fazem parte dos conteúdos que trabalho na sala de aula.

Já, as respostas de P84 e de P37 explicitam uma relação entre ensino, pesquisa e extensão marcada pela complementaridade. P84 afirma que estas atividades se complementam, uma compreende a formação teórica básica, outra a contextualização social e, por fim, a pesquisa proporciona o desenvolvimento social e as possibilidades e/ou tecnologias futuras (grifo nosso). P37 entende as atividades realizadas no ensino, pesquisa e extensão como atividades que se complementam, pois, para ensinar um conhecimento específico, é necessário pesquisa, assim como uma pesquisa pode surgir em função de questões geradas no ensino. Além disso, as atividades de extensão devem ser alimentadas pela pesquisa e vice-versa (grifo nosso).

Selecionamos ainda alguns excertos cuja análise indica haver possibilidades de estabelecimento de uma efetiva relação entre ensino, pesquisa e extensão. Nesse sentido, discorre P17:

Procuro de forma permanente uma relação com a prática social em minhas atividades de ensino e pesquisa. Quando atuo na extensão, me alimento da pesquisa e produzo pesquisa. Assim, a extensão alimenta a pesquisa, a qual alimenta a extensão. $O$ ensino, sempre que possível, ocorre mediado pela pesquisa e pela extensão [...]. Fazemos extensão mediados pelo ensino. Fazemos pesquisa mediados pela extensão. Fazemos ensino mediados pela pesquisa e extensão (grifo nosso). 
P25 afirma:

Os conhecimentos adquiridos pela pesquisa podem desencadear a proposição de novas práticas didático-pedagógicas e/ ou propiciar informações que venham a favorecer os processos de ensino e aprendizagem, bem como podem desencadear a proposição de oficinas elou atividades de extensão. As atividades de extensão, por sua vez, propiciam a vivência de situações e contextos que podem ser benéficas ao trabalho docente e à constituição do ser professor (grifos nossos).

P39 é mais sucinto, mas corrobora, de certa forma, com as ideias dos excertos anteriores: Sim, pois a minha atuação em sala de aula, a minha prática, se reflete e conduz os projetos de pesquisa e qualificam, redimensionam a própria prática. $E$ a extensão está extremamente vinculada a essa temática de ensinar e aprender.

A análise, especialmente dos excertos das respostas de P41, P84, P37, P17, P25 e P39, revela aproximações com o apresentado por Síveres (2013), quando indica que a extensão pode ser compreendida como um jeito de ser, uma maneira de dialogar e uma possibilidade de aprender. Há indicativos de que a essência institucional se mostra na realidade contemporânea por meio de aspectos como contextualização geopolítica, construção do conhecimento e comunicação dos saberes. Revela também diálogos estabelecidos de forma pluri e multidimensional entre instituição e sociedade, pautando o processo educativo como uma ação reflexiva capaz de potencializar a promoção de possibilidades diferenciadas de experiências educativas. A extensão se mostrou como uma possibilidade de aprender, na medida em que se revelou como constitutiva de um eixo transversal para atividades de ensino e de pesquisa, promovendo a articulação entre teoria e prática e a integração entre instituição e sociedade.

Considerando a totalidade das respostas dos sujeitos da pesquisa, a análise indica que, na maioria, os professores explicitam relações possíveis, complementaridade entre ensino, pesquisa e extensão, mas há situações em que essas relações se mostram periféricas e não configuram efetivamente o princípio pedagógico da indissociabilidade. A legislação estabelece a indissociabilidade entre ensino, pesquisa e extensão nas ações de professores universitários, visando ao atendimento de prerrogativas que caracterizam e definem uma IES como universidade. Mas a organização acadêmica de uma universidade por si só não estabelece o referido princípio pedagógico entre as dimensões, como também a natureza constitutiva de cada uma delas por si não institui as relações. É necessário que a IES tenha políticas institucionais materializadas em ações explícitas. Nesse sentido, corroboramos com Dias e Ketzer (2007): 
[...] as relações entre o ensino e a pesquisa não são definidas a partir da natureza em si de cada uma dessas atividades: o processo de trabalho concreto de realização de uma pesquisa é diferente do processo de trabalho concreto de uma situação de ensino. As formas de articulação entre ambos os processos dependem de um conjunto de circunstâncias históricas e variáveis que vão desde as políticas educacionais e científicas, passando pelas condições de recursos, equipamentos, espaços e tempo, chegando até as peculiares idiossincrasias de personalidade dos profissionais que desenvolvem estes trabalhos (DIAS; KETZER, 2007, p. 103, grifo do autor).

A relação entre ensino, pesquisa e extensão não é dada nem pelas características que definem e estruturam a organização acadêmica da IES, nem pela própria natureza das atividades de ensino, de pesquisa e de extensão. Elas dependem de uma construção, de um projeto da IES. E entendemos essa construção como necessária:

As novas demandas da sociedade contemporânea exigem uma formação que articule, com a máxima organicidade, a competência científica e técnica, com a inserção política e a postura ética [...]. Positivamente, a lógica desta formação é a da indissociabilidade entre ensino, pesquisa e extensão. Ensino com extensão aponta para a formação contextualizada às agudas questões da sociedade contemporânea. Ensino com pesquisa aponta para o verdadeiro domínio dos instrumentos nos quais cada profissão se expressa, em seu próprio processo evolutivo. Neste contexto, o conceito da indissociabilidade requerido para o ensino da graduação não se reduz nem ao processo de produção do saber novo, nem às práticas de intervenção direta nos processos sociais, embora não se possa negar a pertinência da pesquisa e extensão em si (FORGRAD, 1999, p. 20-21).

A internalização do conceito de indissociabilidade pelos professores se faz necessária e perpassa pelo estabelecimento de processos que vão muito além de ações individuais. Esses apontamentos vão ao encontro do que propõe Mazzilli (2011, p. 14), quando entende que a concretização da associação entre ensino, pesquisa e extensão demanda:

- a existência de projetos institucionais que anunciem as diretrizes e os compromissos que os orientam e as ações previstas para sua realização;

- a elaboração e o desenvolvimento de projetos coletivos de trabalho, associando ações acadêmicas e administrativas;

- o desenvolvimento de práticas de avaliação institucional abrangendo todo o trabalho realizado pela universidade como instrumento de autoconhecimento institucional;

- a elaboração e a concretização de modelos de gestão que possibilitem a participação de todos os segmentos nos processos de decisão e de avaliação do trabalho acadêmico;

- a constituição de um corpo docente com sólidas formações científica e pedagógica, organicamente vinculado ao projeto da universidade;

- a criação de condições materiais para a realização do projeto pretendido. 


\section{Considerações: extensão, ainda uma atividade a ser reinventada}

A análise do perfil dos professores sujeitos desta pesquisa indica que suas ações como docentes, para além do ensino, envolvem atividades de pesquisa, de extensão e, em menor número, também de gestão. Constatamos, ainda, que o que caracteriza as ações preponderantes deles são efetivamente as atividades de ensino.

Com relação às compreensões que os professores apresentam acerca de suas ações, as análises apontam que eles consideram o ensino como atividade principal ou prioritária desenvolvida pela universidade. Apontam que a associação entre pesquisa, extensão e ensino como desencadeadora de processos de ensino não é explícita nem vivenciada por eles. Há professores que reconhecem a necessidade de atualização constante, considerando sua área específica; outros acreditam que se aprende a ser professor sendo professor.

Um aspecto que consideramos central nas ações que envolvem as atividades de ensino foi abordado por poucos professores: está relacionado ao coletivo do curso e à forma como os diferentes componentes curriculares se articulam na sua efetivação. Outro aspecto que aparece timidamente nas respostas de um professor e que também consideramos como fundante em se tratando da atividade de ensino é a necessidade do aluno; nesse aspecto, levantamos a possibilidade de o professor estar se referindo a como o aluno que está na educação superior aprende. A análise indica, assim, timidamente abordagens para a formação pedagógica do professor universitário, e, nesse sentido, chamamos a atenção à constituição de saberes destes professores, considerando a geração de um espírito científico universal, o que torna imperativo o princípio pedagógico da indissociabilidade entre ensino, pesquisa e extensão.

Sobre a relação que os professores estabelecem entre ensino, pesquisa e extensão, são percebidas diferentes compreensões. As respostas assinalam o estabelecimento de relações entre as atividades de ensino, de pesquisa e de extensão. Em um excerto, um professor que atua em cursos de licenciatura enfatiza a relação entre ensino e extensão; outros dois professores apontam a associação entre atividades de ensino, de pesquisa e de extensão numa relação de complementaridade. Também foram apresentados excertos cuja análise mostra haver possibilidades de estabelecimento de uma efetiva relação entre ensino, pesquisa e extensão, ou seja, relações marcadas pelo princípio pedagógico da indissociabilidade, no qual a extensão constitui-se num eixo transversal, potencializando a promoção de possibilidades de experiências educativas. Mas a análise indica, ainda, situações em que as relações entre ensino, pesquisa e extensão se configuram como periféricas. 
Como resultado, é possível apontar que, apesar de termos considerado como sujeitos da pesquisa professores que atuam em universidades com jornada integral de trabalho, o princípio da indissociabilidade não está, efetivamente, estabelecido; a associação entre ensino, pesquisa e extensão, a partir deste princípio, ainda é frágil. Nesse contexto, há indicativos da compreensão da extensão como uma atividade de diálogo e de aprendizagem entre universidade e sociedade, porém fica explícito que, para a maioria dos professores sujeitos da pesquisa, a extensão ainda é uma atividade a ser reinventada.

\section{Notas}

1 A titulação é condição, mas não suficiente, para o desempenho adequado da docência no ensino superior (FORGRAD, 2004, p. 242).

2 A partir do MEC/Sesu/Capes/Inep.

3 Apresentam programas de formação pedagógica em perspectiva continuada orientados pelos parâmetros de qualidade determinados pelo MEC/Sesu/Capes/Inep.

4 Na disciplina Ensino Superior: perspectivas das ações do professor, ministrada por Cátia Maria Nehring, no Programa de Pós-Graduação em Educação nas Ciências, da Universidade Regional do Noroeste do Estado do Rio Grande do Sul, uma das atividades desenvolvidas foi a aplicação do questionário (anexo) pelos estudantes matriculados; e as respostas ao questionário foram analisadas no transcorrer da disciplina a partir das dimensões do fazer das IES. O questionário, respondido pelo estudante com vínculo com a IES, foi aplicado a outros professores da IES ou a professores conhecidos que concordaram em responder sobre a própria produção acadêmica. No ano de 2017, o banco de dados estava constituído por 101 questionários, envolvendo IES do Rio Grande do Sul e de Santa Catarina e de diferentes organizações acadêmicas. Nesse sentido, os dados produzidos são intencionais a partir do vínculo e das relações dos estudantes matriculados na disciplina. Todos os participantes foram cientificados e notificados de que os dados seriam utilizados para produções acadêmicas e deram seu consentimento, ao participarem como respondentes ao questionário.

\section{Referências}

BRASIL. Decreto $n^{\circ} 5.773$, de 9 maio de 2006. Dispõe sobre o exercício das funções de regulação, supervisão e avaliação de instituições de educação superior e cursos superiores de graduação e sequenciais no sistema federal de ensino. Diário Oficial da União, Brasília, DF, 10 maio 2006.

. Ministério da Educação. Instituto Nacional de Estudos e Pesquisas Educacionais Anísio Teixeira. Censo da Educação Superior. 2016. Disponível em: <http://emec.mec.gov.br/>. Acesso em: $1^{\circ}$ jan. 2017.

Lei $n^{\circ}$ 9.394, de 20 de dezembro de 1996. Estabelece as Diretrizes e Bases da Educação Nacional. Presidência da República. Brasília, DF, 1996.

DEMO, Pedro. Pesquisa participante: saber pensar e intervir juntos. Brasília, DF: Liber Livros. 2004. 
DIAS, Ana Maria Lorio; KETZER, Solange Medina (Org.). Memória do Forgrad - 20 anos do Fórum Nacional de Pró-Reitores de Graduação das Universidades Brasileiras: unidade na diversidade. Porto Alegre: EDIPUCRS, 2007.

FORGRAD. Plano Nacional de Graduação: um projeto em construção. In: FORGRAD. Resgatando espaços e construindo idéias. 3. ed. ampl. Uberlândia: Edufu, 2004. Não paginado.

FORGRAD. Plano Nacional de Graduação: um projeto em construção. In: FÓRUM NACIONAL DE PRÓ-REITORES DE GRADUAÇÃO DAS UNIVERSIDADES BRASILEIRAS, 12., 1999. Ilhéus. Anais... Ilhéus, BA, maio de 1999. Não paginado. Disponível em: <http://www.unicamp. br/prg/forgrad>. Acessado em: 10 jul. 2014.

FRANCO, Maria Amelia Santoro. Prática docente universitária e a construção coletiva de conhecimentos: possibilidades de transformações no processo de ensino-aprendizagem. Cadernos Pedagogia Universitária. Pró-Reitoria de Graduação. São Paulo: USP, 2009. Disponível em: <www. prpg.usp.br/attachments/article/640/Caderno_10_PAE.pdf>. Acesso em: 20 jul. 2016.

GOMES, Magno Federici. Avaliação e natureza administrativa das instituições de ensino superior. Ensaio: avaliação e políticas públicas em educação, Rio de Janeiro, v. 18, n. 68, p. 589-610, jul./set. 2010.

MACIEL, Alderlândia da Silva; MAZZILLI, Sueli. Indissociabilidade entre ensino, pesquisa e extensão: percursos de um princípio constitucional. In: ENCONTRO ANUAL DA ASSOCIAÇÃO NACIONAL DE PÓS-GRADUAÇÃO E PESQUISA EM EDUCAÇÃO, 33., 2010, Caxambu. Anais... Caxambu, MG, 2010. p. 1-13. Disponível em: <http://www.anped.org.br/33encontro/app/ webroot/files/file/Trabalhos\%20em\%20PDF/GT11-6298--Int.pdf>. Acesso em: 22 jul. 2014.

MAZZILLI, S. Ensino, pesquisa e extensão: reconfiguração da universidade brasileira em tempos de redemocratização do Estado. Revista Brasileira de Política e Administração da Educação, Anpae, Goiânia, v. 27, n. 2, p. 205-221, maio/ago. 2011.

MENEZES, Ana Luisa Teixeira; SÍVERES, Luiz. Nas fronteiras da indissociabilidade - a contribuição da extensão universitária. In: SÍVERES, Luiz; MENEZES, Ana Luisa Teixeira. Transcendendo fronteiras: contribuição da extensão das instituições comunitárias de ensino superior (Ices). Santa Cruz do Sul: Edunisc, 2011. p. 49- 65.

MORAES, Roque; GALIAZZI, Maria do Carmo. Análise textual discursiva. 3. ed. Ijuí: Unijuí, 2013.

SAMPAIO, Jorge Hamilton; FREITAS, Marta Helena de. A indissociabilidade entre ensino, pesquisa e extensão. In: FREITAS, Lêda Gonçalves de; MARIZ, Ricardo Spindola; CUNHA FILHO, José Leão da (Org.). Educação superior: princípios, finalidades e formação continuada de professores. Brasília: Líber Livro, 2010.

SÍVERES, Luiz. O princípio da aprendizagem na extensão universitária. In: SÍVERES, Luiz. A extensão universitária como princípio de aprendizagem. Brasília: Liber Livro, 2013.

. Princípios estruturantes da extensão universitária. In: SÍVERES, Luiz; MENEZES, Ana Luisa Teixeira. Transcendendo fronteiras: a contribuição da extensão das instituições comunitárias de ensino superior (Ices). Santa Cruz do Sul: Edunisc, 2011. p. 24-48. 